\title{
OBTENÇÃO DE SUPORTES HÍBRIDOS DE SÍLICA-MONOSSACARÍDEOS, COM POSSÍVEL UTILIZAÇÃO NA IMOBILIZAÇÃO DE PEROXIDASE.
}

\author{
$\underline{\text { Ivan Martins Barreto }}{ }^{1}$; Heiddy Márquez Alvarez²; Maria Antônia Carvalho Lima \\ de Jesus ${ }^{3}$. \\ 1. Bolsista PIBIC/CNPq, Graduando em Química, Universidade Estadual de Feira de Santana, e-mail: \\ ivanmarttins@yahoo.com.br \\ 2. Orientador, Departamento de Ciências Exatas, Universidade Estadual de Feira de Santana, e-mail: \\ marquezheiddy@gmail.com \\ 3. Participante do projeto, Departamento de Ciências Exatas, Universidade Estadual de Feira de Santana, e-mail: \\ airamcarvalho@gmail.com
}

PALAVRAS-CHAVE: imobilização; suporte híbrido; monossacarídeos.

\section{INTRODUÇÃO}

A imobilização de enzimas em suportes híbridos mesoporosos (orgânico e inorgânico) atualmente apresenta um grande potencial, devido as melhores características do material quando comparadas a seus componentes separadamente. A síntese destes suportes híbridos pode ser realizada através da funcionalização pós-sintética (enxerto), a co-condensação ou na forma de organosílicas mesoporosas (ADAM et al., 2012).

Diversos suportes inorgânicos de sílicas mesoporosas como, por exemplo, as sílicas SBA-15 e MCF já foram utilizados para a imobilização de peroxidase de raiz forte ou horseradishperoxidase (HRP), que é uma enzima de grande interesse em virtude das inúmeras possibilidades de aplicação (CAO et al., 2012). A HRP livre e/ou imobilizada apresenta diversas aplicações que unidas à sua elevada atividade, simplicidade na detecção e relativa estabilidade motiva o desenvolvimento de novos biocatalisadores que aumentem a estabilidade da mesma. Contudo a HRP possui um alto preço no mercado. A peroxidase de rabanete (Raphanus sativus) - RAP possui estrutura semelhante a HRP e pode ser utilizado como fonte alternativa de peroxidases. Considerando os estudos sobre imobilização de peroxidase extraída de rabanete (Raphanus sativus), verificou-se que não existem relatos na literatura quanto ao uso de suportes híbridos (inorgânico e orgânico) possibilitando um novo estudo que abarque a obtenção de novos suportes para a imobilização de enzimas econômicas com diversas aplicabilidades.

\section{METODOLOGIA}

\section{Extração da enzima do rabanete}

A enzima foi extraída das raízes do rabanete (Raphanus sativus) comprado no comércio local. As raízes foram lavadas com água e tiradas à pele e cortadas em pedaços pequenos. Utilizamos $30,0 \mathrm{~g}$ das raízes trituramos e homogeneizamos em um triturador com $100 \mathrm{~mL}$ de tampão fosfato $(0,05 \mathrm{~mol} / \mathrm{L}) \mathrm{pH} 6,5$ por 30 segundos. Adicionamos 65 $\%(\mathrm{v} / \mathrm{v})$ de acetona fria á mistura obtida anteriormente, até precipitação da enzima. A mistura foi armazenada na temperatura de congelamento $\left(-18{ }^{\circ} \mathrm{C}\right)$ por 24 horas. Após este tempo, fizemos a centrifugação da mistura a $4{ }^{\circ} \mathrm{C}$ por $15 \mathrm{mim}$. O precipitado contendo a peroxidase foi coletado e submetido à remoção da acetona por evaporação em banho gelado por 24 horas e após foi liofilizada, sendo então utilizada para os testes de imobilização (CHAGAS, 2014). 


\section{Síntese de suportes híbridos de sílica e monossacarídeo}

A obtenção dos suportes híbridos foi realizada utilizando a metodologia dos suportes das sílicas SBA-15 e MCF modificada (CHOUYYOK et al., 2009). Utilizamos a glicose e a frutose como o aditivo orgânico (AD) e o tetraetilortosilicato (TEOS) como a parte inorgânica. Para o preparo dos suportes híbridos de sílica SBA-15 modificado, utilizamos 0,5 ou 1,0 g do monossacarídeo, em $30 \mathrm{~mL}$ de água destilada e $585 \mu \mathrm{L}$ de ácido clorídrico concentrado $(\mathrm{HCl})$. Em seguida, $5 \mathrm{~mL}$ de TEOS foram adicionados à solução. A solução foi mantida sob agitação à temperatura ambiente até a completa homogeneização. A mistura foi colocada em um sistema reacional com banho de óleo de silicone, acoplado a um condensador de refluxo e permaneceu a $80{ }^{\circ} \mathrm{C}$ durante 24 horas. A mistura obtida ao final do processo foi filtrada e lavada com água destilada até $\mathrm{o} \mathrm{pH}$ neutro. $\mathrm{O}$ material sintetizado foi seco à temperatura ambiente por 24 horas e armazenado. A quantidade de monossacarídeo que não reagiu foi determinada pelo método Lane e Eynon, conforme Tavares et al. (2010), no qual utilizamos o fluído oriundo da reação, obtido na filtração do sólido obtido.

\section{Imobilização da peroxidase por Adsorção física (AF)}

A RAP e a HRP foram imobilizadas por adsorção física (AF) em híbridos de sílica SBA-15 modificada. A imobilização foi conduzida em tampão fosfato $\left(\mathrm{Na}_{2} \mathrm{HPO}_{4} \cdot 2 \mathrm{H}_{2} \mathrm{O}\right)$ $100 \mathrm{mM}, \mathrm{pH} 7,0$, meio que propicia maior eficiência de imobilização conforme a literatura. O efeito do carregamento da enzima na faixa de 0,10 - 0,5 $\mathrm{mg}$ de enzima/g de suporte foi avaliado para imobilização da RAP e HRP nos suportes sintetizados.

$\mathrm{Na}$ metodologia de imobilização por adsorção física (AF) o suporte seco foi suspenso em $1 \mathrm{~mL}$ de tampão fosfato e mantido sob agitação mecânica por 15 minutos, em seguida foi adicionado $1 \mathrm{~mL}$ da solução de RAP ou de $\operatorname{HRP}(0,1 \mathrm{mg} / \mathrm{mL})$ preparada em tampão fosfato de sódio $100 \mathrm{mM}, \mathrm{pH} \mathrm{7,0} \mathrm{no} \mathrm{carregamento} \mathrm{de} \mathrm{enzima} \mathrm{desejado.} \mathrm{O}$ sistema foi mantido em um shaker sob agitação de $150 \mathrm{rpm}$ por 3 horas a $30^{\circ} \mathrm{C}$, em seguida, foi armazenado a $4{ }^{\circ} \mathrm{C}$ em condição estática, durante 24 horas. Finalmente, o biocatalisador, suporte com a enzima adsorvida, foi filtrado e lavado com tampão para retirada de enzimas não adsorvidas até o volume de $6 \mathrm{~mL}$ e o filtrado foi reservado para quantificação da atividade enzimática.

\section{Determinação da atividade peroxidásica}

A atividade enzimática de RAP e da HRP foi determinada conforme o método de utilizado por Hirata et al. (1998) que é baseado na mudança de absorvância a $470 \mathrm{~nm}$ devido à formação do produto de oxidação do guaiacol, o tetraguaiacol durante três minutos (Etetraguaiacol: $26,6 \mathrm{mM}^{-1} \mathrm{~cm}^{-1}$ ). O ensaio contém 2,75 $\mathrm{mL}$ de tampão fosfato de sódio $100 \mathrm{mM}$ (pH 7,0); 0,05 mL da solução enzimática, diluída quando necessário, em tampão $\mathrm{pH} 7,0 ; 0,1 \mathrm{~mL}$ de solução de guaiacol $100 \mathrm{mM}$ e $0,1 \mathrm{~mL}$ de peróxido de hidrogênio $\left(\mathrm{H}_{2} \mathrm{O}_{2}\right) 2,0 \mathrm{mM}$ a $25^{\circ} \mathrm{C}$. Uma unidade de enzima (U) foi definida como a quantidade de enzima capaz de fornecer $1 \mu \mathrm{mol}$ de produto em 1 minuto a $25^{\circ} \mathrm{C}$ em $\mathrm{pH}$ 6,0 .

A eficiência de imobilização (\%) e o número de unidades de enzima imobilizada (U) foram determinados pela diferença entre número de unidades de atividade peroxidásica oferecidas (Uo) e o número de unidades de enzima remanescente no filtrado (Uf), conforme Eq. 


\section{RESULTADOS E DISCUSSÃO}

A síntese dos suportes híbridos silicato-monossacarídeo ocorreu de forma satisfatória. Foram obtidos quatro suportes, utilizando glicose e frutose como aditivo orgânico (AO), Figura 1.

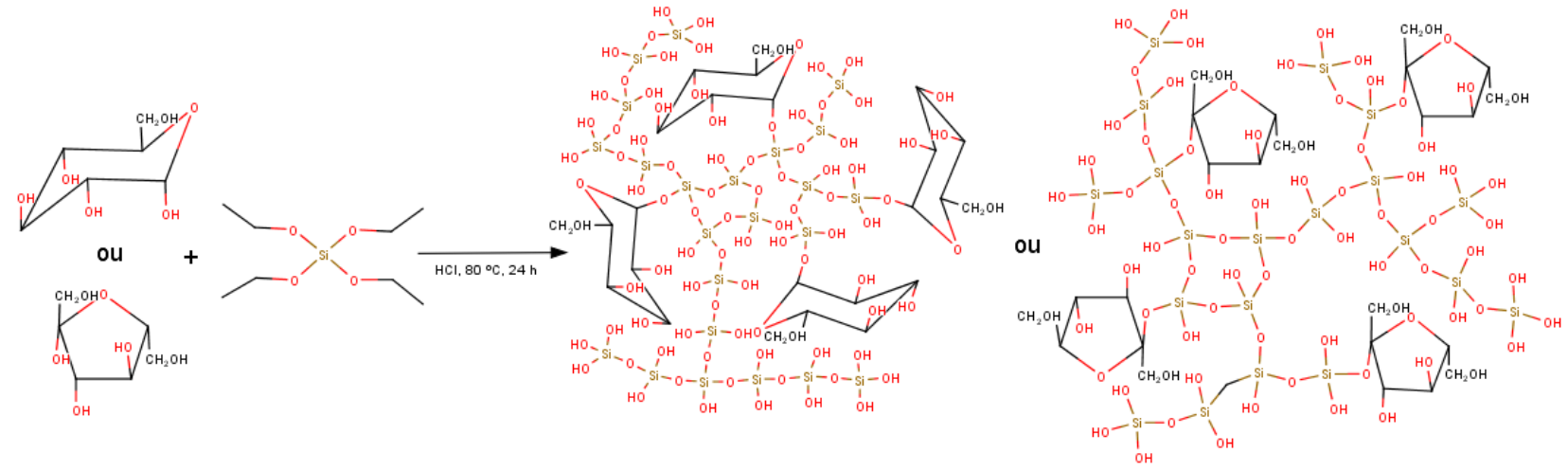

Figura 1. Reação de síntese do suporte híbrido sílica-monossacarídeo.

A determinação da quantidade de monossacarídeo que não reagiu foi determinado pelo método de Lane e Eynon. Os resultados são apresentados na tabela 1.

Tabela 1. Resultados obtidos na síntese dos suportes híbridos sílica-monossacarídeo.

$\begin{array}{llll}\text { Suporte } & \text { AO } & \text { Massa de } \text { AO no suporte obtida (g) }\end{array}$

\begin{tabular}{llll}
\hline GA & Glicose $(1,0 \mathrm{~g})$ & 35,3 & 1,86 \\
\hline FA & Frutose $(1,0 \mathrm{~g})$ & 34,9 & 1,88 \\
\hline GB & Glicose $(0,5 \mathrm{~g})$ & 49,8 & 1,86 \\
\hline FB & Frutose $(0,5 \mathrm{~g})$ & 59,0 & 1,97 \\
\hline
\end{tabular}

Na tabela 1 se observa que a quantidade de aditivo orgânico não influencia na massa de suporte obtida, no entanto se influencia na quantidade de monossacarídeo presente no suporte.

A RAP foi substituída pela HRP, pois apresentou baixa atividade, o que pode ser justificado pela desnaturação parcial da enzima no processo de extração ou durante o manuseio do extrato bruto.

A HRP foi imobilizada por adsorção física (AF) no suporte híbrido silicatomonossacarídeo do tipo A. O efeito do carregamento de HRP $(1-5 \mathrm{mg}$ de HRP/g de suporte) na imobilização da HRP em suporte híbrido por AF é mostrado nas Figuras 1 e 2.
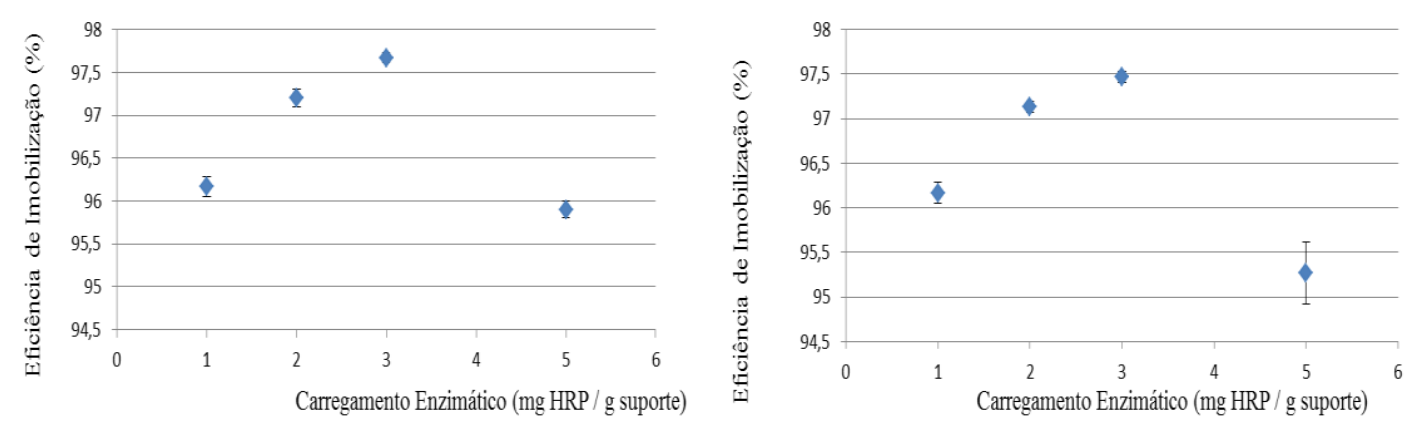

Figura 2. Eficiência de imobilização no suporte GA e no suporte FA, respectivamente. 
As Figuras acima mostram que no método de imobilização por AF usando o suporte híbrido A, apresentou um aumento, relativamente pequeno, na eficiência de imobilização com o aumento no carregamento, no intervalo de 1 a $5 \mathrm{mg}$ de $\mathrm{HRP} / \mathrm{g} \mathrm{de}$ suporte, assim concluímos que o carregamento enzimático tem pouca influência na eficiência de imobilização.

A imobilização de HRP por AF foi estudada por Queiroz et al. (2014) utilizando o bagaço de cana-de-açúcar como suporte e por Jesus et al. (2017) utilizando suporte híbrido alginato-silicato. Para o primeiro a eficiência de imobilização foi constante, em torno de $30 \%$, com carregamento entre 0,125 e $2 \mathrm{mg}$ de HRP/g suporte, e em carregamento superior (2,5 mg de HRP/g suporte) ocorreu uma diminuição na eficiência para $19 \%$ e o segundo concluiu que a melhor eficiência de imobilização foi no carregamento de $2 \mathrm{mg}$ de HRP / g de suporte. Contudo, os suportes em análise apresentaram maior eficiência de imobilização no carregamento de $3 \mathrm{mg}$ de HRP / g de suporte, sendo $97 \%$ de eficiência no suporte tipo GA e no suporte tipo FA e decaindo para $95 \%$ no carregamento de $5 \mathrm{mg} \mathrm{HRP} / \mathrm{g}$ de suporte em ambos biocatalisadores.

\section{CONSIDERAÇÕES FINAIS}

A quantidade de aditivo orgânico utilizado na síntese do suporte híbrido influência diretamente na quantidade de monossacarídeos presente no filtrado, contudo não influencia na quantidade de suporte obtida, desta forma, é possível usar menores quantidades de aditivos orgânicos, a fim de evitar a produção de volumes maiores de rejeitos. A eficiência de imobilização da enzima HRP no suporte híbrido mostrou-se satisfatória. Os valores de eficiência mostraram-se crescentes até o limite de saturação do suporte. O carregamento de $3 \mathrm{mg}$ de HRP/g suporte foi considerado ideal para imobilização do suporte em estudo.

\section{REFERÊNCIAS}

ADAM, F.; APPATURI, J. N.; IQBAL, A. The utilization of rice husk silica as a catalyst: Review and recent progress, Catalysis Today, 190, p. 2 - 14, 2012.

CHAGAS, P. M. B. Estabilidade catalítica da peroxidase de nabo na forma livre e imobilizada em esferas de quitosana. Lavras. UFLA, 2014.

CAO, S; AITA, G.M. Enzymatic hydrolysis and ethanol yields of combined surfactante and dilute ammonia treated sugarcane bagasse, Bioresource Technology, 131, p. 357364, 2013.

CHOUYYOK, W.; PANPRANOT, J.; THANACHAYANANT, C.; PRICHANONT, S. Effects of $\mathrm{pH}$ and pore characters of mesoporoussilicas on horseradish peroxidase immobilization, Journal of Molecular Catalysis B: Enzymatic, 56, p. 246 - 252, 2009.

HIRATA, T.; IZUMI, S.; OGURA, M.; YAWATA, T. Epoxidation of styrenes with the peroxidase from the culture cells of Nicotianatabacum, Tetrahedron, 54, p. 15993 16003, 1998.

JESUS, M. A. C. L; Imobilização da peroxidase de raiz forte (HRP) em suporte híbrido sílica-alginato e em amberlite IRA 67 impregnada com íons cobre: potencialidades do biocatalisador imobilizado na biodegradação do corante índigo carmim. Tese de doutorado - Programa de Pós-graduação em Biotecnologia, da Universidade Estadual de Feira de Santana. Feira de Santana - BA. 2017.

QUEIROZ, M. L. B. Imobilização de Peroxidase de raiz forte por adsorção física e ligação covalente em bagaço de cana de açúcar. Dissertação de Mestrado Biotecnologia Industrial. Aracaju - SE, 2014.

TAVARES, J. T. Q.; CARDOSO, R. L.; COSTA, J. A.; FADIGAS, F. S. F.; FONSECA, A. A. Interferência do ácido ascórbico na determinação de açúcares redutores pelo método de Lane e Eynon. Quim. Nova, Vol. 33, No. 4, 805-809, 2010. 